\title{
Is Anxiety and Depression Related with Personality in Caregivers for Patients with Bipolar Disorder?
}

\author{
Enver Demirel Yilmaz ${ }^{1^{*}}$, Erdem Deveci ${ }^{1}$, Hüseyin Güleç ${ }^{2}$, Ali Görkem Gençer ${ }^{3}$, Özge Ünal ${ }^{4}$, Emel Koçer ${ }^{1}$ and İsmet Kırpınar $^{1}$ \\ 1Department of Psychiatry, Faculty of Medicine, Bezmialem Vakif University, Istanbul, Turkey \\ 2Department of Psychiatry, Erenköy Training and Research Hospital for Psychiatric and Neurological Diseases, Istanbul, Turkey \\ 3Department of Psychiatry, Başak şehir State Hospital, Istanbul, Turkey \\ 4Department of Psychiatry, Istanbul Education and Research Hospital, Istanbul, Turkey
}

*Corresponding author: Enver Demirel Yılmaz, MD, Department of Psychiatry, Faculty of Medicine, Bezmialem Vakif University, Adnan Menderes Avenue 34083 Fatih / Istanbul, Turkey, Tel: +9 021245317 00, +9 050552490 56; Fax: +9 021262175 80; E-mail: enveryilmaz6@yahoo.com.tr

Received date: March 7, 2014, Accepted date: April 26, 2014, Published date: May 5, 2014

Copyright: ( 2014 Yılmaz ED, et al. This is an open-access article distributed under the terms of the Creative Commons Attribution License, which permits unrestricted use, distribution, and reproduction in any medium, provided the original author and source are credited.

\begin{abstract}
Objective: The objective of this study is to analyse the correlation between state and trait anxiety, depression and personality traits in caregivers of patients diagnosed with bipolar affective disorder.
\end{abstract}

Method: The study sample consists of care-givers of 34 patients diagnosed with bipolar affective disorder according to the DSM IV-TR criteria, and 37 healthy voluntary subjects demographically matched. The Temperament and Character Inventory (TCI), Hamilton Depression Rating Scale (HDRS) and State-Trait Anxiety Inventory (STAIX I-II) scales have been applied to the subjects.

Results: In this study, it has been found that STAIX-I and STAIX-II anxiety scores are higher in caregivers. The comparison between the groups has revealed that persistence $(P)$ scores are higher in caregivers $(P<0.001)$. $A$ statistically significant correlation has been found between the STAIX -I score and harm avoidance (HA) Score $(r=0.36, P=0.04)$; STAIX-II score and harm avoidance (HA) $(r=0.57, P<0.001)$; self-transcendence (ST) ( $r=0.41$, $P=0.01)$ and self-directedness (SD) scores $(r=-0.60, P<0.001)$; HDRS score and harm avoidance (HA) ( $r=0.47$, $\mathrm{P}=0.01)$ of $\mathrm{TCl}$

Conclusion: Our results suggest that considering their personality traits, caregivers of patients with bipolar affective disorder should be assessed by clinicians more carefully and comprehensively in respect of anxiety.

Keywords: Bipolar affective disorder; Caregivers; Anxiety; Temperament; Depression

\section{Introduction}

Chronic psychiatric diseases are mental health problems that affect caregivers as much as patients themselves. Bipolar Affective Disorder $(B A D)$ is a chronic disease which progresses with relapses and remissions. Although the patients may have remission periods, the attacks cause severe symptoms that require hospitalization, thus severely affecting caregivers [1]. In Turkey, most patients live with their families who are in charge of their care without any outside support after such periods of hospitalization [2]. Various studies indicate that caregivers of chronic psychiatric patients develop depressive symptoms and anxiety frequently as a result of constant stress [3]. Naturally, such psychological problems of caregivers affect the treatment process negatively [1]. Nowadays, treatment of chronic psychiatric diseases extends beyond the borders of traditional physician-patient relationship, becoming a broader process that also involves the patients' relatives. This development increased the families' responsibilities as caregivers during post-rehabilitation process. As a result, there is an increased interest in the literature about the relation between the psychiatric disorders and the caregivers' behaviors [4]. Nowadays, it is a widely accepted fact that the caregivers have an essential role in the treatment process [5]. Caregivers are one of the three basic components of treatment along with the patient and healthcare professionals. Therefore, cooperation with caregivers becomes even more important for the sustainability of treatment.

Various studies on BAD patients and their relatives indicate that negative attitudes and reactions by the society are perceived as stigmatization by caregivers, resulting in fear of social isolation.

Aggressive and homicidal behavior and symptoms like excessive sexual activity observed during the episodes of BAD can cause stigmatization during the remission periods, creating extra burden on the patients and caregivers [6].

Personality traits are the most important determinants of caregivers' emotional or behavioral reaction to their caregiving responsibilities.

Treating the psychiatric problems of caregivers along with those of the patients themselves is essential for more effective treatment. Therefore, it is vital for the clinician to evaluate the personalities of caregivers and thus predict the correlation between these personality traits and the possible emergence of mental health problems like anxiety and depression. This study aims to analyze the relation between the state and trait anxiety levels, as well as depression levels of 
Citation: Yilmaz ED, Deveci E, Gulec H, Gencer GA, Unal O, Kocer E, et al. (2014) Is Anxiety and Depression Related with Personality in Caregivers for Patients with Bipolar Disorder?. J Psychiatry 17: 122. doi:10.4172/Psychiatry .1000122

Page 2 of 6

caregivers and their personality traits by considering the burden of caregivers who try to contribute to the treatment process effectively. The study focuses on the anxiety levels and personality traits of caregivers rather than subjects like patient burden, stigmatization, depressive symptoms and expressed emotions $[7,8]$ commonly found in literature.

\section{Materials and Methods}

This study is conducted as part of a wider study aimed to better understand the burden imposed on patients' relatives by chronic psychiatric disorders. The sample group consisted of caregivers of 34 patients diagnosed with BAD according to the DSM IV-TR criteria and hospitalized due to manic episodes, and 37 healthy volunteers who match the caregivers in terms of age, gender and education. Inclusion criteria of the study are being in charge of caregiving directly, literacy in Turkish with a sufficient level of education. Exclusion criteria are caregivers who receive psychiatric treatment, who have a chronic disease history (Diabetes mellitus, chronic heart disease, chronic renal failure, asthma, thyroid diseases, etc.) or regularly use prescribed drugs. 74 candidates were scanned during the preparation phase of the study. Three individuals were excluded since they did not meet the criteria and thus the study was conducted with 71 subjects. The ethics of the study was assessed and the necessary permission was given by the Educational Planning Committee. Written consents of all participants were obtained in the beginning of the study.

\section{Materials}

Socio-demographic data sheet, State and Trait Anxiety Inventory (STAIX I-II), Temperament and Character Inventory (TCI) were applied to all participants. All the inventories are self-assessment inventories personally filled in by the participant. Only the Hamilton Depression Rating Scale (HDRS) was applied by the researcher.

Cloninger's Temperament and Character Inventory (TCI): TCI is a self-assessment inventory created by Cloninger et al. The inventory consists of 240 "TRUE or FALSE" questions [9]. The validity and reliability of TCI's Turkish version were performed by Kose and colleagues [10].
Hamilton Depression Rating Scale (HDRS): This scale, which rates the severity of depression and mood changes, was created by Max Hamilton and updated by Janet Williams [11]. The scale consists of 17 items. Ratings of 14 and above indicate depression. The validity and reliability of the scale's Turkish version were performed by Akdemir and colleagues [12]. The researcher's knowledge in psychopathology is important for successful application of the test.

Spielberger's State-Trait Anxiety Inventory (STAIX I-II): This inventory developed by Spielberger and his colleagues consists of two sub-scales (state and trait), each consisting of 20 questions: 1 . State Anxiety Inventory (STAIX I): Determines how the individual feels at a specific time under specific conditions. 2. Trait Anxiety Inventory (STAIX II): Determines how the individual feels independently from his/her present state and conditions [13]. It's a simple self-inventory. The inventory's Turkish version was prepared by Öner and Le Compte [14].

\section{Statistical Analyses}

The conformity of data with normal distribution was analyzed using the Kolmogorov Smirnov test. The Chi-square test was used to determine proportional variables for demographic and clinical variable comparisons between the sample groups, while the Student $\mathrm{T}$ test was used to determine continuous variables. The correlation between the STAIX I-II and HDRS data of TCI sub-inventories was analyzed using the Spearman Correlation Analysis. The data was presented in average \pm standard deviation and as percentages. The statistical significance limit was assumed as $\mathrm{p}<0.05$.

\section{Results}

$41.2 \%$ of the 34 caregivers included in the study were women. The average age of participants is $41.03 \pm 11.02$. Seven caregivers $(20.6 \%)$ were the parents of the patients, $11(32.4 \%)$ were siblings or children and $16(47 \%)$ were spouses. The average patient care duration was found to be $6.94 \pm 5.29$ years. $29.7 \%$ of the 37 healthy participants who demographically matched the caregivers were women. The average age of the control group is $37.11 \pm 10.04$. The demographic attributes of both groups are shown on the following Table 1.

\begin{tabular}{|c|c|c|c|}
\hline & Caregivers $(n=34)$ & Controls $(n=37)$ & $\mathbf{p}$ \\
\hline Age $(\text { Years })^{*}$ & $41.03 \pm 11.02$ & $37.11 \pm 10.04$ & 0.25 \\
\hline $\begin{array}{l}\text { Gender }(\%)^{\star *} \\
\text { Female } \\
\text { Male }\end{array}$ & $\begin{array}{l}41.2 \% \\
58.8 \%\end{array}$ & $\begin{array}{l}29.7 \% \\
70.3 \%\end{array}$ & 0.313 \\
\hline $\begin{array}{l}\text { Marital Status }(\%)^{\star *} \\
\text { Never Married } \\
\text { Married } \\
\text { Divorced }\end{array}$ & $\begin{array}{l}8.8 \% \\
79.4 \% \\
11.8 \%\end{array}$ & $\begin{array}{l}37.4 \% \\
57.2 \% \\
5.4 \%\end{array}$ & 0.38 \\
\hline $\begin{array}{l}\text { Financial Status }(\%)^{\star *} \\
\text { Poor } \\
\text { Middle Class } \\
\text { Upper-Middle Class } \\
\text { Rich }\end{array}$ & $\begin{array}{l}5.9 \% \\
32.4 \% \\
35.3 \\
26.5 \%\end{array}$ & $\begin{array}{l}\% 4.3 \% \\
32.1 \% \\
40.4 \% \\
23.2 \%\end{array}$ & 0.95 \\
\hline
\end{tabular}


Citation: Yilmaz ED, Deveci E, Gulec H, Gencer GA, Unal O, Kocer E, et al. (2014) Is Anxiety and Depression Related with Personality in Caregivers for Patients with Bipolar Disorder?. J Psychiatry 17: 122. doi:10.4172/Psychiatry .1000122

Page 3 of 6

\begin{tabular}{|l|l|l|l|}
\hline Education (years) & $9.53 \pm 4.23$ & $9.78 \pm 4.12$ & 0.91 \\
\hline $\begin{array}{l}\text { Working Status (\%)* } \\
\text { Working }\end{array}$ & $47.1 \%$ & $52.9 \%$ & 0.63 \\
\hline
\end{tabular}

Table 1: Socio-demographical features. ${ }^{*}$ Student $\mathrm{t}$ test, ${ }^{* *}$ chi-square test.

The comparison of clinical variable between groups is shown on Table 2. The results indicate that both state and trait anxiety averages are higher in caregivers, while there is no significant difference between the average depression scores of the groups. The temperament and character inventory results show that the $\mathrm{P}$ averages are statistically higher in caregivers, while there are no significant differences in any other dimension.
The correlation analysis between clinical variables is shown on Table 3. It was observed that the state anxiety scores are statistically correlated to the HA temperament trait, while trait anxiety scores are correlated with the HA, SD and ST traits.

\begin{tabular}{|l|l|l|l|l|}
\hline & Caregivers & Controls & T & p \\
\hline STAIX-I & $39.91 \pm 11.69$ & $33.47 \pm 5.82$ & 3.42 & 0.001 \\
\hline STAIX-II & $43.79 \pm 10.75$ & $37.04 \pm 5.33$ & 3.17 & 0.003 \\
\hline HDRS & $2.85 \pm 2.61$ & $2.74 \pm 2.30$ & & 0.20 \\
\hline TCI Subscale & & & -1.33 & -0.84 \\
\hline Novelty Seeking & $17.74 \pm 4.21$ & $19.11 \pm 5.51$ & 1.78 & 0.19 \\
\hline Harm Avoidance & $15.15 \pm 5.12$ & $16.36 \pm 7.90$ & 4.10 & 0.40 \\
\hline Reward Dependence & $15.53 \pm 2.71$ & $14.43 \pm 3.26$ & 0.14 & 0.08 \\
\hline Persistence & $5.71 \pm 1.29$ & $4.47 \pm 2.09$ & 1.61 & $<0.001$ \\
\hline Self Directedness & $29.79 \pm 7.43$ & $29.59 \pm 7.21$ & -1.59 & 0.89 \\
\hline Cooperativeness & $32.18 \pm 4.78$ & $30.57 \pm 5.12$ & $20.79 \pm 5.33$ & 0.11 \\
\hline Self Transcendence & $17.82 \pm 5.50$ & & 0.11 \\
\hline
\end{tabular}

Table 2: Comparison of the groups according to STAIX-I and II, HDRS and TCI scores, STAIX-I and II: Spielberger's state and trait anxiety inventory, HDRS: Hamilton depression rating scale, TCI: Cloninger's temperament and character inventory

The correlation between the duration of care giving for caregivers and the relevant variables are shown in Table 3. The relation of care giving duration with the mentioned variables was not found to be at a statistically significant level.

\begin{tabular}{|l|l|l|l|l|l|l|l|l|}
\hline \multirow{2}{*}{ TCI Subscales } & \multicolumn{3}{l}{ STAIX-I } & \multicolumn{2}{l}{ STAIX-II } & \multicolumn{2}{l|}{ HDRS } & \multicolumn{2}{l|}{ Duration of Caregiving } \\
\cline { 2 - 11 } & $\mathrm{r}$ & $\mathrm{p}$ & $\mathrm{r}$ & $\mathrm{p}$ & $\mathrm{r}$ & $\mathrm{p}$ & $\mathrm{r}$ & $\mathrm{p}$ \\
\hline Novelty Seeking & -0.16 & 0.36 & -0.01 & 0.95 & -0.26 & 0.14 & 0.17 & 0.33 \\
\hline Harm Avoidance & 0.36 & 0.04 & 0.57 & $<0.001$ & 0.47 & 0.01 & -0.03 & 0.87 \\
\hline Reward Dependence & -0.13 & 0.46 & -0.03 & 0.87 & -0.03 & 0.88 & -0.01 & 0.97 \\
\hline Persistence & -0.23 & 0.19 & -0.32 & 0.07 & -0.19 & 0.27 & 0.14 & 0.41 \\
\hline Self Directedness & 0.05 & 0.79 & -0.60 & $<0.01$ & -0.32 & 0.07 & 0.09 & 0.61 \\
\hline Cooperativeness & -0.14 & 0.43 & -0.14 & 0.42 & -0.18 & 0.32 & -0.12 & 0.48 \\
\hline
\end{tabular}




0.28

0.12

0.41

0.01

0.30

0.08

$-0.18$

0.32

Table 3: Correlations between TCI and STAIX-I / II, HDRS and Durations of Care giving, TCI:Cloninger's temperament and character inventory, STAIX-I and II: Spielberger's state and trait anxiety inventory, HDRS: Hamilton depression rating scale.

\section{Discussion}

Anxiety is a basic human emotion, a sophisticated emotional state and an adaptive mechanism used to cope with danger. Anxiety caused by imminent and temporary danger is defined as "state anxiety", while internal anxiety that makes the individual feel threatened at the core and react to his/her current situation with increased stress is defined as "trait anxiety". This approach was first introduced with Cattel and Scheier's study on factor analysis and later became the basis of the Dual Conceptualization of Anxiety developed by Spielberger and colleagues [14]. Based on this approach, our study evaluates the anxiety scores of caregivers according to STAIX I and II. The study revealed that the state and trait anxiety scores (as defined by Spielberger) of caregivers were higher than those of the control group.

Due to its chronic nature and the disruptions it causes in the patient's thoughts and perception, BAD leads to a variety of problems like stigmatization, aggression, lack of insight and economic consequences arising from loss of professional abilities [15]. Such problems impose a significant burden on caregivers, which can be compared to that caused by schizophrenia. Since patients with BAD can act and function normally, except for symptomatic episodes, caregivers' responsibilities are fewer and less frequent than those caregivers of schizophrenia patients [16]. However, BAD may cause more severe symptoms in some patients, imposing an additional burden on caregivers and families. When compared to the healthy control group, it is observed that caregivers of patients with BAD suffer from impaired quality of life due to psychological strain, social and role adjustment problems [17]. It is also reported that BAD imposes burdens not only on caregivers, but all family members. A recent study revealed that $90 \%$ of family members of patients with $\mathrm{BAD}$ reported heavy subjective and objective burden, and that economic burden persist even during the asymptomatic phases [18].

Two separate studies aimed to analyze the anxiety and depression states of caregivers of long time schizophrenia patients revealed that the anxiety and depression scores of the patients' relatives are higher than the healthy control group $[19,20]$. BAD studies reveal similar results with $27.6 \%$ of caregivers displaying depression symptoms and $45.5 \%$ displaying clear anxiety symptoms [21]. Another study revealed that one third of caregivers display clear depression symptoms and that nearly half were unsatisfied with their lives. The same study concluded that the level of depression and stress of caregivers is correlated with the amount of time spent with the patient, career interruption, relationship problems and aggressive behavior by the patient [22].

In contrast to high levels of depression frequently reported in literature, our study revealed similar levels of depression between caregiver and control groups. A study conducted by Chessicket al. revealed that depression levels in caregivers of BAD patients with higher depression levels and suicidal tendencies are significantly higher than those who care for patients without depressive symptoms. The same study reveals that the caregivers of patients whose levels of depression and suicidal tendencies increase in time display more depression symptoms than those in charge of relatively stable or improving cases [23].

A study conducted by Heru and Ryan reveals that the caregiving responsibilities of individuals taking care of $\mathrm{BAD}$ patients significantly decrease after one year, while the responsibilities of caregivers of depressive patients stay the same [24]. The fact that all patients included in our study were in manic phases may explain why the depression levels of caregivers were similar to those of the control group. As an alternative approach, it may be concluded that since the caregivers have been taking care of the patients for long periods (6.94 \pm 5.29 years in average), they may have adapted to the situation well enough to deal with the depression symptoms.

The higher anxiety scores observed in caregivers in our study may be considered a result of the stigmatization and social isolation they suffered or social problems they encounter due to the state and behavior of the patients. A study conducted by Lee e al. revealed a correlation between the anxiety scores of caregivers of BAD patients and the anxiety levels of the patient, stigmatization and insufficient cooperation in terms of treatment [21]. It was also revealed that caregivers of $\mathrm{BAD}$ patients receive more frequent psychiatric treatments. Logistic regression analysis reveals that the burden on caregivers is correlated with the use of psychiatric and primary healthcare institutions even after medical problems are controlled [25].

Our study also aims to determine whether the anxiety levels observed in caregivers are related with personality traits or not. In our literature research, we could not find any study that analyses the relation between the personality traits and psychopathology in caregivers or relatives of BAD patients. However, we have found a study that assesses the temperament and character dimensions defined by Cloninger in caregivers and relatives of BAD patients. This study, conducted by Almeida and colleagues, compared immediate family members of BAD patients with a healthy control group and revealed that family members had higher HA scores and lower SD scores. $20.6 \%$ of caregivers included in our study are parents of the patients, while $32.4 \%$ are siblings or children and $47 \%$ are spouses. The fact that almost half of our sample consists of spouses - who are not genetically related to the patients-may explain why the $\mathrm{P}$ scores are higher than the control group and why there was no difference in other dimensions [26].

According to Cloninger, $\mathrm{P}$ reflects a hereditary tendency to persist in the face of difficulties, fatigue and obstacles. Persistent people are industrious, determined and ambitious. This ambition reflects their tendency to overcome fatigue and obstacles [27]. Chen et al. stated that lower P scores are associated with depression and that such scores can be used to predict the development of depression [28]. The fact that the $\mathrm{P}$ scores of caregivers were higher than those of the control group may explain the lack of depression symptoms.

Our study revealed a meaningful statistical correlation between HA and state anxiety scores, as well as between HA, SD and ST and trait anxiety scores. 
Cloninger defines HA as a heritable bias in the inhibition of behavior in response to signals of punishment and frustration [27]. It is observed as pessimistic worry in anticipation of problems, fear of uncertainty, shyness with strangers, and rapid fatigability. Almost all studies analyzing the relationship between $\mathrm{HA}$ and anxiety state a strong and positive correlation between the two [29,30] and that nucleus accumbens may play a key role in this relationship [31].

Cloninger et al. state that SD is correlated with both depression and anxiety [32]. Furthermore, SD was found to be connected with all personality disorder classifications [33]. In summary, low SD scores point to problems or a general susceptibility underlying all mental disorders. Individuals with low self-directedness scores are accusatory, help-seeking, irresponsible, insecure and reactive [27]. Studies analyzing the relation between SD and anxiety reveal that individuals with low SD scores are more susceptible to anxiety and frequently suffer from anxiety disorders $[29,30,34]$. A study conducted by Tanaka and colleagues reveals that SD scores can be used to predict high anxiety scores even after depression scores are checked [35].

According to Cloninger, Self-Transcendent individuals are just, understanding and modest [27]. It can be argued that in their relationships with their patients, caregivers of $\mathrm{BAD}$ patients display supportive and selfless behaviors that match their anxiety scores, and that they avoid selfish attitudes and behavior. These individuals may be suffering from anxiety due to the uncertainties and pessimism caused by the state of their patients and the sense of injustice caused by deteriorated personal and social life. Studies that analyze the relation between ST and anxiety have often reported a positive correlation between high ST scores and anxiety [36,38].

As a limitation to this study, in fact it is not completely true to match a healthy control group with the caregivers of $\mathrm{BAD}$, since approximately $50 \%$ genetic transition is seen in $\mathrm{BAD}$. It would have been more appropriate to assess the caregivers over time and compare the results (in a before-and-after or timed study). However, since our study is not longitudinal but cross-sectional, we have evaluated the duration of caregivers in correlation with the relevant variables.

\section{Conclusion}

Our results suggest that assessing caregivers and BAD patients in a holistic manner in respect to anxiety and personality traits is an effective approach that can positively contribute to the treatment process.

\section{Acknowledgements}

The authors state no conflict of interest. The study was not supported by any funding sources. This study is submitted to World Psychiatric Association International Congress Istanbul 2013 as a poster abstract.

\section{References}

1. Canan B (2008) the inpatients in psychosis services' and their caregiver's ideas and recommendations about stepped care system (In Turkish). Bolu: AbantIzzetBaysal University.

2. Öztürk O (1988) Mental Health and disorders. (In Turkish) Ankara: Nobel Medical Press.

3. Duman Z, Bademli K (2013) Families of Chronic Psychiatric Patients: A Systematic Review. Current Approaches in Psychiatry 5: 78-94.
4. Atagün Mİ, Balaban ÖD, Atagün Z, Elagöz M, Özpolat AY (2011) Caregiver Burden in Chronic Diseases. Current Approaches in Psychiatry 3: 513-552.

5. Brown S, Birtwistle J (1998) People with schizophrenia and their families: Fifteen-year outcome. Br J Psychiatry 173: 139-144.

6. Fadden G, Bebbington P, Kuipers L (1987) Caring and its burdens. A study of the spouses of depressed patients.Br J Psychiatry 151: 660-667.

7. Hinrichsen GA, Lieberman JA (1999) Family attributions and coping in the prediction of emotional adjustment in family members of patients with first-episode schizophrenia. Acta Psychiatr Scand 100: 359-366.

8. Hooley JM, Campbell C (2002) Control and controllability: beliefs and behaviour in high and low expressed emotion relatives. Psychol Med 32: 1091-1099.

9. Cloninger CR, Svrakic DM, Przybeck TR (1993) A psychobiological model of temperament and character. Arch Gen Psychiatry 50: 975-990.

10. Köse S, Sayar K, Ak İ, Aydin N, Reeves RA, et al. (2004) Temperament and character inventory (Turkish TCI): validity, reliability and factor structure. Clinical Psychopharmocology Bulletin (In Turkish) 14: 107-131.

11. Williams JB (1988) A structured interview guide for the Hamilton Depression Rating Scale. Arch Gen Psychiatry 45: 742-747.

12. AkdemirA, Örsel S, Dağ İ, Türkçapar H (1996) Validity, Reliability and The Clinical Use of Hamilton Depression Rating Scale. Journal of Psychiatry, Psychology (In Turkish) 4: 251-259.

13. Spielberger C, Gorsuch RL, Lushene RD (1970) Manual for the state-trait anxiety inventory. Palo Alto, CA: Consulting Psychologists Press.

14. Öner N (1977) The validity of state-trait anxiety inventory in a Turkish culture (In Turkish). Ankara: Hacettepe University.

15. Beentjes TA, Goossens PJ, Poslawsky IE (2012) Caregiver burden in bipolar hypomania and mania: a systematic review. Perspect Psychiatr Care 48: 187-197.

16. Aydemir Ö (2004) Attitudes and stigmatization toward Bipolar disorder (In Turkish). Journal of Psychiatry, Psychology and Psychopharmacology 12: 1-4.

17. Zendjidjian X, Richieri R, Adida M, Limousin S, Gaubert N, et al. ( 2012) Quality of life among caregivers of individuals with affective disorders. J Affect Disord 136: 660-665.

18. Maji KR, Sood M, Sagar R, Khandelwal SK (2012) A follow-up study of family burden in patients with bipolar affective disorder. Int $\mathrm{J}$ Soc Psychiatry 58: 217-223.

19. Oldridge ML, Hughes IC (1992) Psychological well-being in families with a member suffering from schizophrenia. An investigation into longstanding problems.Br J Psychiatry 161: 249-251.

20. Gibbons JS, Horn SH, Powell JM, Gibbons JL (1984) Schizophrenic patients and their families. A survey in a psychiatric service based on a DGH unit. Br J Psychiatry 144: 70-77.

21. Lee AM, Simeon D, Cohen LJ, Samuel J, Steele A, et al. (2011) Predictors of patient and caregiver distress in an adult sample with bipolar disorder seeking family treatment. J Nerv Ment Dis 199: 18-24.

22. Rodrigo C, Fernando T, Rajapakse S, De Silva V, Hanwella R (2013) Caregiver strain and symptoms of depression among principal caregivers of patients with schizophrenia and bipolar affective disorder in Sri Lanka. Int J Ment Health Syst 7: 2.

23. Chessick CA, Perlick DA, Miklowitz DJ, Dickinson LM, Allen MH, et al. (2009)Suicidal ideation and depressive symptoms among bipolar patients as predictors of the health and well-being of caregivers. Bipolar Disord 11: 876-884.

24. Heru AM, Ryan CE (2004) Burden, reward and family functioning of caregivers for relatives with mood disorders: 1-year follow-up. J Affect Disord 83: 221-225.

25. Perlick DA, Hohenstein JM, Clarkin JF, Kaczynski R, Rosenheck RA (2005) Use of mental health and primary care services by caregivers of patients with bipolar disorder: a preliminary study. Bipolar Disord 7: 126-135. 
Citation: Yilmaz ED, Deveci E, Gulec H, Gencer GA, Unal O, Kocer E, et al. (2014) Is Anxiety and Depression Related with Personality in Caregivers for Patients with Bipolar Disorder?. J Psychiatry 17: 122. doi:10.4172/Psychiatry.1000122

Page 6 of 6

26. Almeida KM, Nery FG, Moreno RA, Gorenstein C, Lafer B (2011) Personality traits in bipolar disorder type I: a sib-pair analysis. Bipolar Disord 13: 662-669.

27. Cloninger CR (1987) A systematic method for clinical description and classification of personality variants. A proposal. Arch Gen Psychiatry 44: 573-588.

28. Chen Z, Lu X, Kitamura T (2011)The effects of temperament and character on symptoms of depression in a chinese nonclinical population. Depress Res Treat 198591: 17.

29. Mertol S, Alkin T (2012) Temperament and character dimensions of patients with adult separation anxiety disorder. J Affect Disord 139: 199-203.

30. Cloninger CR, Zohar AH, Hirschmann S, Dahan D (2012)The psychological costs and benefits of being highly persistent: personality profiles distinguish mood disorders from anxiety disorders. J Affect Disord 136: 758-766.

31. Levita L, Hoskin R, ChampiS (2012) Avoidance of harm and anxiety: a role for the nucleus accumbens. Neuroimage 62: 189-198.

32. Cloninger CR, Bayon C, Svrakic DM (1998) Measurement of temperament and character in mood disorders: a model of fundamental states as personality types. J Affect Disord51: 21-32.
33. Svrakic DM, Whitehead C, Przybeck TR, Cloninger CR (1993) Differential diagnosis of personality disorders by the seven-factor model of temperament and character. Arch Gen Psychiatry 50: 991-999.

34. Minelli A, Pedrini L, Magni LR, Rotondo A (2009) Personality traits in an italian sample: relationship with anxiety and depression. Clin Pract Epidemiol Ment Health 5: 26-30.

35. Tanaka E, Sakamoto S, Kijima N, Kitamura T (1998) Different personalities between depression and anxiety. J ClinPsychol54: 1043-1051.

36. Jaksic N, Brajkovic L, Ivezic E, Topic R, Jakovljevic M (2012) The Role of Personality Traits in Posttraumatic Stress Disorder (PTSD). Psychiatr Danub 24: 256-266.

37. Mortberg E, Bejerot S, Aberg Wistedt A (2007) Temperament and character dimensions in patients with social phobia: patterns of change following treatments? Psychiatry Res 152: 81-90.

38. Matsudaira T, Kitamura T (2006) Personality traits as risk factors of depression and anxiety among Japanese students. J Clin Psychol 62: 97-109. 